\title{
Prophylactic “First-Step” Central Neck Dissection (Level 6) Does not Increase Morbidity After (Total) Thyroidectomy
}

\author{
Iain J. Nixon, MBChB, FRCS (ORL-HNS), PhD \\ Department of Otolaryngology Head and Neck Surgery, NHS Lothian, Edinburgh, UK
}

\section{TO THE EDITORS}

Selberherr et al. presented a detailed analysis of outcome following prophylactic level 6 neck dissection (pCND). ${ }^{1}$ However, the reader should be cautious before applying these findings to their practice. pCND has always been controversial in papillary thyroid cancer (PTC), because it does not affect survival. The exposure required for pCND is similar to that required for thyroidectomy alone, and revision surgery has long been associated with higher complication rates. Therefore, many authors recommend pCND.

Readers should note that in this paper, the surgical group's definition of pCND does not conform to the 2009 consensus statement, which defines the central neck as extending from carotid to carotid artery, rather than recurrent laryngeal nerve (RLN) to RLN. ${ }^{2}$ Groups with experience of revision central neck surgery in PTC report the highest rates of recurrent disease in areas not addressed with this approach. ${ }^{3}$

Volume is closely associated with complication rates. In high-volume hands, the increase in morbidity associated with pCND is minimal. This is not true when outcomes are analysed in a more general setting. ${ }^{4}$
A recent meta-analysis calculated that the number-needed-to-treat with pCND was 31 to avoid 1 recurrence. ${ }^{5}$ The surgeon must consider whether with a 1-in-31 chance that proceeding with pCND will be beneficial in terms of recurrence (not survival) to their patient, are their personal complication rates sufficiently low to take the chance?

\section{REFERENCES}

1. Selberherr A, Riss P, Scheuba C, Niederle B. Prophylactic "firststep" central neck dissection (level 6) does not increase morbidity after (total) thyroidectomy. Ann Surg Oncol. 2016;23(12):4016-22.

2. Carty SE, Cooper DS, Doherty GM, et al. Consensus statement on the terminology and classification of central neck dissection for thyroid cancer. Thyroid. 2009;19(11):1153-58.

3. Clayman GL, Agarwal G, Edeiken BS, Waguespack SG, Roberts DB, Sherman SI. Long-term outcome of comprehensive central compartment dissection in patients with recurrent/persistent papillary thyroid carcinoma. Thyroid. 2011;21(12):1309-16.

4. Chadwick D, Kinsman R, Walton P. The British Association of Endocrine \& Thyroid Surgeons Fourth National Audit Report. Dendrite Clinical Systems Ltd, The Hub, Station Road, HenleyonThames, Oxfordshire RG9 1AY, United Kingdom; 2012.

5. Wang TS, Cheung K, Farrokhyar F, Roman SA, Sosa JA. A metaanalysis of the effect of prophylactic central compartment neck dissection on locoregional recurrence rates in patients with papillary thyroid cancer. Ann Surg Oncol. 2013;20(11):3477-83.

(C) Society of Surgical Oncology 2017

First Received: 13 October 2017;

Published Online: 27 October 2017

I. J. Nixon, MBChB, FRCS (ORL-HNS), PhD

e-mail: Iain.nixon@nhs.net 